\title{
Study of Serum Electrolyte Levels in Type 2 Diabetes Mellitus
}

\author{
A.M. Siddiqui ${ }^{1}$, Swati K. Choudhary ${ }^{* 2}$ \\ ${ }^{1}$ Associate Professor, Biochemistry, Dr.S.C.Govt. Medical college, Nanded Post code - 431606, India \\ ${ }^{2}$ Assistant Professor, Biochemistry, Dr.S.C.Govt. Medical college, Nanded Post code - 431606, India \\ *Correspondence Author: Swati K. Choudhary; choudharyswa@ rediffmail.com
}

Received 24 May 2019;

Accepted 21 June 2019;

Published 26 June 2019

\begin{abstract}
Introduction: The incidence of diabetes mellitus is increasing rapidly with interference in electrolytes sodium $\left(\mathrm{Na}^{+}\right)$, potassium $\left(\mathrm{K}^{+}\right)$and chloride $\left(\mathrm{Cl}^{-}\right)$. The prevalence of diabetes mellitus is rapidly rising all over the globe at an alarming rate. Objective: Study of serum electrolyte levels in type 2 Diabetes Mellitus. Material and methods: Total of 100 subjects were included in the study, out of which two groups were formed; 50 type 2 diabetes mellitus patients and 50 controls. Centrifuged serum was analyzed for estimation of $\mathrm{Na}^{+}, \mathrm{K}^{+}$and $\mathrm{Cl}^{-}$level by the Accustar auto analyzer. $\underline{\text { Results: }}$ In type 2 diabetes mellitus serum $\mathrm{Na}^{+}$level was observed significantly decreased while $\mathrm{Cl}^{-}$and $\mathrm{K}^{+}$levels were increased. Both the electrolytes $\left(\mathrm{Na}^{+} \mathrm{Cl}^{-}\right)$differ significantly in diabetes and control group. Conclusion: Electrolyte metabolism is disturbed in type 2 diabetes mellitus and proper glycemic control and evaluation of electrolyte levels can reduce the fatalities associated with electrolyte derangement in type 2 diabetes mellitus.
\end{abstract}

Keywords: Type 2 diabetic mellitus, Serum sodium $\left(\mathrm{Na}^{+}\right)$, Serum potassium $\left(\mathrm{K}^{+}\right)$, serum chloride $\left(\mathrm{Cl}^{-}\right)$

\section{Introduction}

Diabetes mellitus is a metabolic disorder characterized by chronic hyperglycemia due to derangement in carbohydrate, fat and protein metabolism that are associated with absolute or relative deficiencies in insulin secretion, insulin action or both ${ }^{[1]}$. Diabetes is an iceburg disease. The prevalence of diabetes for all age groups worldwide was estimated to be $2.8 \%$ in 2000 with 171 million people affected and is expected to rise to 366 million (4.4\%) in $2030^{[2]}$. Sodium, Potassium, Calcium and Chloride are some of the major macro minerals present in body taking part in intermediatory metabolism and enzyme activities ${ }^{[3]}$. Disturbances in serum electrolyte levels are found to be associated with Diabetes Mellitus ${ }^{[4]}$. Electrolytes plays an important role in many processes like acid base balance, controlling body fluids, blood clotting, muscle contractions. The disturbed electrolyte distribution may affect the course of diabetes and its management ${ }^{[5]}$.

\section{Material and Methods}

The study was carried out at Dr. S. C. Govt. Medical College, Vishnupuri, Nanded. A total of 50 clinically diagnosed subjects and 50 controls were studied. An informed consent was taken from all studied subjects. $5 \mathrm{ml}$ of venous blood collected from antecubital vein from each of the subjects. The whole blood samples were allowed to clot and for serum separation blood samples were centrifuged. This centrifuged serum was analyzed for estimation of $\mathrm{Na}^{+}, \mathrm{K}^{+}$and $\mathrm{Cl}^{-}$level by the Accustar auto analyzer.

\section{Statistical Analysis}

Data were represented as mean $\pm \mathrm{SD}$ values. Student's t-test was performed to find out differences between diabetic and control groups. The $\mathrm{P}$ value $<0.05$ was considered to be significant.

\section{Results}

Table 1: Comparison of different parameters between type $2 \mathrm{DM}$ and control group

\begin{tabular}{|l|c|c|c|}
\hline \multicolumn{1}{|c|}{ Parameters } & Type 2 DM $(\mathbf{n}=\mathbf{5 0})$ mean \pm SD & Control groups $(\mathbf{n = 5 0})$ mean \pm SD & p-Value \\
\hline${\text { Serum } \mathrm{Na}^{+}(\mathrm{mmol} / \mathrm{L})}$ & $107.82 \pm 12.45$ & $144.44 \pm 6.80$ & $<0.0001$ \\
\hline Serum $\mathrm{K}^{+}(\mathrm{mmol} / \mathrm{L})$ & $6.36 \pm 0.58$ & $4.42 \pm 0.71$ & $<0.0001$ \\
\hline Serum $\mathrm{Cl}^{-}(\mathrm{mmol} / \mathrm{L})$ & $122.38 \pm 15.52$ & $100.48 \pm 5.05$ & $<0.0001$ \\
\hline
\end{tabular}

\section{Discussion}

Electrolyte imbalance occurs in diabetes patients from insulin deficiency, hyperglycemia and hyperketonemia ${ }^{[6]}$. Hyperglycemia in diabetes causes shifting of water from intracellular space to extracellular space diluting the extracellular $\mathrm{Na}^{+}$leading to lower serum $\mathrm{Na}^{+}$level ${ }^{[7]}$. Alteration in rennin angiotensin system in diabetes leads to change in serum sodium concentration ${ }^{[8]}$. Physiologically $\mathrm{Na}^{+}$is reabsorbed in proximal tubule of kidney and 
excessive urination due to hyperglycemia is known to be the mechanical cause of decreased $\mathrm{Na}^{+}$concentration ${ }^{[9]}$.

Diabetes associated hyperkalemia has multiple causes such as reduced glomerular filtration, redistribution of potassium from intracellular to extracellular compartment and alterations in the $\mathrm{Na}^{+} / \mathrm{K}^{+}$ATPase that maintained the transmembrane gradients of sodium and potassium. The incidence of hyperkalemia is higher in diabetic patients than in the general population ${ }^{[10,11]}$. Nevertheless, the most common causal factor of chronic hyperkalemia in diabetics is the reduced tubular secretion of $\mathrm{K}^{+}$due to the syndrome of hyporeninemic hypoaldosteronism ${ }^{[12]}$.

The serum $\mathrm{Cl}^{-}$value in the diabetic group was significantly increased compared to control group. Diabetic ketoacidosis may be responsible for elevated chloride level in type 2 diabetes patient. Keto-acids reduce blood $\mathrm{pH}$ disturbing acid base balance and leads to elevation of chloride. Similar findings was observed in a previous published study ${ }^{[13]}$.

\section{Conclusion}

The present study showed reduced $\mathrm{Na}^{+}$and elevated $\mathrm{K}^{+}$and $\mathrm{Cl}^{-}$ levels more significantly in patients having type 2 diabetes mellitus.

Therefore early detection of diabetic complication by proper evaluation of serum electrolyte levels along with good glycemic control reduces the fatalities resulting from electrolyte imbalance.

\section{Conflicts of Interest}

There is no conflict of interest regarding the publication of this paper.

\section{Funding Statement}

This research article is done in our Dr. S.C. Govt. Medical College and Hospital, Nanded. No financial help is taken from any financially supporting body for this research article.

\section{Acknowledgements}

I am thankful to type 2 diabetes mellitus patients for their cooperation especially for collection of blood samples. I equally acknowledge the co-operation of colleagues and co-staff. The support of the professional staff and the laboratories are also acknowledged.

\section{References}

[1] Alberti, K.G. and P.Z. Zimmet,1998, Definition.

[2] Wild S, Roglic G, Green A, Sicree R, King H. Global prevalence of diabetes-estimates for the year 2000 and projections for 2030. Diabetes Care 2004;27(5):1047-53.

[3] Lobo DN. Fluid, electrolytes and nutrition: Physiological and clinical aspects. Proc Nutr Soc. 2004;63(3):453-466.

[4] Shenqi Wang, Xuhong Hou, Yu Liu, Huijuan Lu, Li Wei, Yuquian Bao, Weiping Jia (2013). Serum Electrolyte Levels in Relation to Macrovascular Complications in Chinese Patients with Diabetes Mellitus. Cardiovascular Diabetology. 12(146): 1-10)

[5] Rao GM. Serum electrolytes and osmolality in diabetes mellitus. Indian J Med Sci 1992;46(10):301-3.

[6] Kitabchi AE, UmpierreGE, Murphy MB, Kriesberg RA. Hyperglycemic crisis in adult patientswiyh diabetes: a consensus statement from the American diabetes association. Diabetes Care 2006;29(12):2739-48.

[7] Palmer BF, Clegg DJ. "Electrolyte and Acid-Base Disturbances in Patients with Diabetes Mellitus.” N Engl J Med. 2015;373(6):548-59. 1:133-2422.

[8] Tuck ML, Sambhi MP, Levin L. Selective hyporeninism and hypoaldosteronism in diabetes mellitus: Studies of the auto- nomic nervous system control of renin release. Diabetes. 1979;28:237-246.9.

[9] Vallon V, Ritcher K, Blantz RC, Thomson S, Oswald H. Glomerular hyperfiltration in diabetes mellitus: a potential role of tubular reabsorption. J Am Soc Nephrol, 1999;10(12):2569-76.

[10] Palmer BF. Managing hyperkalemia caused by inhibitors of the renin-angiotensin-aldosterone system. N Engl J Med. 2004;351:585-592.

[11] Uribarri J, Oh MS, Carroll HJ. Hyperkalemia in diabetes mellitus. J Diabet Complications. 1990;4:3-7.

[12] De Fronzo RA. Hyperkalemia and hyporeninemic hypoaldosteronism. Kidney Int. 1980;17:118-134.

[13] N. Al-Jameil. "Estimation of Serum Electrolytes in Diabetes Patients of Saudi Region.” Life. Sci. J. 2014; 11(7): 378-380. 